\title{
Correction to: Diversity in Surgery: A Historical, International, and Contemporary Perspective
}

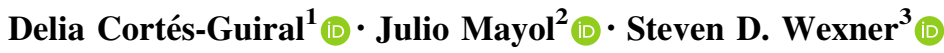

Published online: 17 June 2021

(C) Springer Science+Business Media, LLC, part of Springer Nature 2021

\section{Correction to: Curr Surg Rep (2021) 9:14 \\ https://doi.org/10.1007/s40137-021-00289-3}

The original version of the article unfortunately contained a few errors.

In the Abstract, under 'Summary', the term 'Sexual preferences' should read as 'Sexual orientation' in the sentence, "Social media has emerged as a democratizer...". The corrected sentence is given below,

"Social media has emerged as a democratizer, giving voice to all surgeons regardless of gender identification, race, nationality, ethnicity, religious beliefs, sexual orientation, or other demographic factors."

The original article can be found online at https://doi.org/10.1007/ s40137-021-00289-3.

Delia Cortés-Guiral

delia.cortes.guiral@gmail.com

1 King Khalid University Hospital, Alkhalidiyyah, Najran 66262, NJ, Saudi Arabia

2 Hospital Clinico San Carlos, Instituto de Investigación Sanitaria San Carlos, Universidad Complutense, Madrid, Spain

3 Cleveland Clinic Florida, Weston, FL, USA
Under the header "Time for a New Normal for Underrepresented Surgeons", the term 'Sexual preferences' should read as 'Sexual orientation' in the sentence, "Surgery is a field in which talent must prevail...". The corrected sentence is given below,

"Surgery is a field in which talent must prevail over considerations of gender, sexual orientation, religious preferences, or race."

Publisher's Note Springer Nature remains neutral with regard to jurisdictional claims in published maps and institutional affiliations. 